\title{
APPROPRIATE USER ACCEPTANCE CRITERIA FOR NEW SOCIAL MEDIA SITES
}

\author{
Mirsat Yeşiltepe \\ Department of Mathematical Engineering, \\ Yıldız Technical University. \\ mirsaty@yldiz.edu.tr
}

\begin{abstract}
Nowadays social media sites have attracted many of users and they have become the mostly commonly used websites for public. These websites are used by individuals, small and even big organizations for various purposes, such as meeting your old friends, sharing your own experiences, sharing pictures and videos, promoting businesses, sharing knowledge etc. Their popularity is increasing at an increasing rate. User's needs are endless so there will be some new area for creating new social media sites. There are two main ideas for creating new social media sites. Firstly, one should identify the new needs of users which are not fulfilled by the current websites. Secondly, the new website must incorporate those features which are mostly liked by end users and add further functionality into the website that attract more users. It is important to know the criteria based on which the users prefer one website over the other. Therefore, the objective of this study is to compare the use of social media and find the acceptance criteria that why an end user prefers one social media over the other. This user feedback based information will help social media developers to incorporate new user needs into future social media to increase user satisfaction. We performed experiments on data collected fifteen most commonly used and popular social media websites in current era. The test data were collected till May 08, 2016.
\end{abstract}

Keywords: Social media sites, sloppy mail, accessing from devices.

\section{Introduction}

Security was problem yesterday. Security is problem today. Security will be a problem tomorrow. There is no area of security is not a problem [1]. With cloud technology, the border of security is getting wider because of the new area is usable from different kind of devices that user use like personal computer, mobile devices, some watch. Every device is different but they want to be at same security level and sometimes some want more secure environment. So, the social media sites must be same security level for every kind of devices. Social media sites are more usable for mobile devices. Since personal computers can be used 
different people while mobile devices are personal. But users want to join the sites with personal computers also.

It is social media accounts more than half of Internet users in the world. This account serves most users to access on mobile devices. As time progresses, the ratio of PCs to be much later than the trend rate of the Internet to connect other devices to show momentum despite declining mobile users connect to the Internet though is that although accelerating rate second among all connected [2].

Member is a member of the site accepting some of the potential difficulties in accepting some of the steps are provided. This will be the biggest cause of active sites next to the security problem that may occur is to try not to members of the user. Because the only purpose of the site is to have active addition to having many of members. Given that there has not been tested for purposes of comparison names on social media sites.

Table 1. Social media site rating of sequencers and the relationship between the number of users [3]

\begin{tabular}{|c|c|c|c|c|c|}
\hline Ranking & Ranker 1 & Ranker 2 & Ranker 3 & Ranker 4 & User Number \\
\hline 1 & 3 & 3 & 3 & 2 & 1100000000 \\
\hline 2 & 12 & 21 & 8 & 8 & 310000000 \\
\hline 3 & 18 & 25 & 19 & 9 & 255000000 \\
\hline 4 & 22 & 27 & 13 & 26 & 250000000 \\
\hline 5 & 30 & 32 & 28 & - & 120000000 \\
\hline 6 & 34 & 55 & 13 & 34 & 110000000 \\
\hline 7 & 77 & 49 & 145 & 36 & 100000000 \\
\hline 8 & 97 & 150 & 120 & 21 & 80000000 \\
\hline 9 & 123 & 138 & 139 & 91 & 65000000 \\
\hline 10 & 581 & 237 & 335 & 1172 & 42000000 \\
\hline 11 & 596 & 791 & 701 & 296 & 40000000 \\
\hline 12 & 702 & 1082 & 615 & 408 & 38000000 \\
\hline 13 & 779 & 2046 & 113 & 179 & 37000000 \\
\hline 14 & 1457 & 1407 & 635 & 2328 & 15500000 \\
\hline 15 & 1487 & 153 & 258 & 4022 & 15000000 \\
\hline
\end{tabular}

Table 1 rating with the number of users of various social media sites are shown. Rankers rating given to the site of the site is different. This is because only the number of users used the site for sorting data. The purpose of the study is to decide the site of the sorter site uses the criteria of acceptance about the ranking member of the site.

Social media sites are more usable for mobile devices. Since personal computers can be used different people while mobile devices are personal. But users want to join the sites with 
personal computers also. Today different kinds of devices also want to join social media sites like special watch also used with communicate with other people in real time.

Authentication and authorization are two concepts that are compared. User authentication is correct about the connection of the site to determine the user's authority regarding the relevant authorization on the site [4][5]. The right to access the user is a common goal of both concepts. Authorization can remain connected while the user how the system, the system tries to solve problems, such as what level can use to which resources.

\section{Captcha using}

Captcha (Completely Automated Public Turing test to tell Computers and Humans Apart) is one way to make sure that a non-human actor is not trying to interact with the media as human being. It basically displays some alpha numeric on a distorted image so that bots should not be able to find the exact values. Although this is a good way to distinguish between humans and machines [6]. However, it has been also criticized for being complex process. Therefore, to ease the users many of popular websites which are more popularity have not incorporated in their websites as a security measure.

Table 2. Social media site rating of sequencers and the relationship between the number of users

\begin{tabular}{|c|c|}
\hline Ranking & Captcha Using \\
\hline 1 & Unavailable \\
\hline 2 & Unavailable \\
\hline 3 & Unavailable \\
\hline 4 & Unavailable \\
\hline 5 & Unavailable \\
\hline 6 & Used \\
\hline 7 & Unavailable \\
\hline 8 & Unavailable \\
\hline 9 & Used \\
\hline 10 & Unavailable \\
\hline 11 & Unavailable \\
\hline 12 & Unavailable \\
\hline 13 & Unavailable \\
\hline 14 & Used \\
\hline 15 & First not later used \\
\hline
\end{tabular}

Captcha has lot of kind like image verification purposes, including common, text verification, has various types like to ask the answer [7]. Verification is done by voice, usually for people with disabilities when using captcha. When using, captcha is usually having two problems. Related verification tool needs cannot be processed by machines. That is why quality is a complex mechanism can be seen. But it will also prompt users to use the captcha. It must exist an optimal ratio between them [8].

To summaries above table for new ones should first not using later using of captcha. Aim of that if there is attacker it will be catched second one. It seems bad things. For not attacker person captcha is unwanted thing. It takes time to continue. 


\section{Other social media sites supporting}

The new social media sites offer users to $\log$ in to their social media application using other sites as well. Although this features is good from user's perspective with ease of use but, on the other side it causes a risk for applications that they should rely on other sites for authentication. So the new site have to construct the rules which sites are reliable. Make collaborating with other sites is best way to increasing user number and the users will rely the new site.

Social media sites can be grouped. Therefore, users may want to subscribe to multiple social media sites. It is desirable in this case. As an example, some social media sites, another social media site was created for a special occasion. Purpose cannot be used for all requests through a single social media site [9].

Table 3. Relations with other social media sites to be considered members of the social media site rating

\begin{tabular}{|c|c|}
\hline Ranking & Other social media sites supporting \\
\hline 1 & - \\
\hline 2 & - \\
\hline 3 & - \\
\hline 4 & 1 \\
\hline 5 & - \\
\hline 6 & - \\
\hline 7 & 1 \\
\hline 8 & 1 \\
\hline 9 & Mail \\
\hline 10 & 2 \\
\hline 11 & 1, mail \\
\hline 12 & 1, mail \\
\hline 13 & 1, mail, \\
\hline 14 & 1 \\
\hline 15 & 1 \\
\hline
\end{tabular}

In Table 3 most of the sites make other social media sites supporting. But the most popular ones don't support it yet. Since they want to be independent. They have many users than others. The new ones can't get many users directly. The sites ought to accept directly other user of other sites.

\section{Password attributes}

There is a conflict of interest between user and social media website on password. Users tend to keep short and simple passwords so that they can easily remember it. On the other hand, websites require users to follow some strict criteria for setting passwords such as minimum length, mix of capital and small letters with numbers, special characters etc. Although, a strong password is more difficult to guess or break, however, it makes user unsatisfied because they usually prefer simpler passwords over complex ones. 
Passwords to be known by others is a very important and personal information than necessary. However, users of this information to remember or too good to be stored in an environment of this type of information may be necessary as a problem to users [10].

Table 4. Social media site with a minimum rating requirements for password length and special characters using the relationship

\begin{tabular}{|c|c|c|}
\hline Ranking & $\begin{array}{c}\text { Minimum password } \\
\text { legth }\end{array}$ & $\begin{array}{c}\text { Have to use special } \\
\text { characters in password }\end{array}$ \\
\hline 1 & 8 & Have to \\
\hline 2 & 6 & Not have to \\
\hline 3 & 6 & Not have to \\
\hline 4 & 6 & Not have to \\
\hline 5 & 8 & Have to \\
\hline 6 & 8 & Not have to \\
\hline 7 & 6 & Have to \\
\hline 8 & 8 & Have to \\
\hline 9 & 9 & Not have to \\
\hline 10 & 6 & Not have to \\
\hline 11 & 6 & Not have to \\
\hline 12 & 6 & Have to \\
\hline 13 & 8 & Not have to \\
\hline 14 & 8 & Have to \\
\hline 15 & 8 & \\
\hline
\end{tabular}

Close to the future social media sites when connecting to the user's mobile device authentication code can be considered for use. The aim is to use another user's request about the situation is not right next to the user code [11].

\section{Phone number necessary}

Nowadays many websites make it a strict criterion to enter a valid phone number for cross validation during the time of registration. However, many users are reluctant to give their personal numbers to any social media site. The best way in this scenario is to offer the phone number as an optional step so that user can decide which is better for user.

Social media sites usually seek validation through mobile devices. The reason for this is to ensure that members have the right to non-users of the system. The system is intended to prevent the use of malicious users. The users do not deny that is another reason [12]. When prompted by the user rather than the $\mathrm{PC}$ is much easier to communicate with mobile devices. 
Table 5. Wanting the phone number of social media sites and the rating may register with a different country code phone number

\begin{tabular}{|c|c|c|}
\hline Ranking & $\begin{array}{c}\text { Request a phone } \\
\text { number }\end{array}$ & $\begin{array}{c}\text { Telephone number of } \\
\text { different countries }\end{array}$ \\
\hline 1 & Optional & Accept \\
\hline 2 & Request & Accept \\
\hline 3 & Not request & No \\
\hline 4 & Not request & No \\
\hline 5 & Optional & No \\
\hline 6 & Not request & Accept \\
\hline 7 & Optional & Accept \\
\hline 8 & Request & Accept \\
\hline 9 & Request & Accept \\
\hline 10 & Optional & No \\
\hline 11 & Not request & No \\
\hline 12 & Not request & Accept \\
\hline 13 & Not request & No \\
\hline 14 & Request & \\
\hline 15 & Not request & \\
\hline & & \\
\hline
\end{tabular}

\section{Phone number necessary}

A primary email is necessary for all social sites for registration. Most of the websites send an email to their users for verification. This means the user should provide a valid email to register to the website. Most of the websites user their email as user name. However, some websites allow users to select a separate username for their login other than email address. Popular social websites allow users to use their phone numbers also to login to their social media.

Some sites only use confirmation mail from mobile devices not from personal computers as mobile devices are more personal. 
Table 6. Relationship between social media ranking corporate e-mail support, in fact no email, popular e-mail account support, sloppy mail and confirmation mail

\begin{tabular}{|c|c|c|c|c|c|}
\hline Ranking & $\begin{array}{l}\text { Corporate e- } \\
\text { mail support }\end{array}$ & $\begin{array}{c}\text { In fact no e- } \\
\text { mail }\end{array}$ & $\begin{array}{c}\text { Popular e- } \\
\text { mail account } \\
\text { support }\end{array}$ & Sloopy mail & $\begin{array}{c}\text { Confirmation } \\
\text { mail }\end{array}$ \\
\hline 1 & Yes & Can access & Yes & Yes & Yes \\
\hline 2 & Yes & Can access & Yes & Yes & $\begin{array}{c}\text { From } \\
\text { telephone }\end{array}$ \\
\hline 3 & Yes & Can access & Yes & No & Yes \\
\hline 4 & Yes & Can access & Yes & Yes & No \\
\hline 5 & Yes & $\begin{array}{c}\text { Can not } \\
\text { access }\end{array}$ & $\begin{array}{l}\text { Just about } \\
\text { particular e- } \\
\text { mail account }\end{array}$ & No & Yes \\
\hline 6 & Yes & Can access & Yes & Yes & Yes \\
\hline 7 & Yes & $\begin{array}{c}\text { Only } \\
\text { telephone }\end{array}$ & $\begin{array}{c}\text { Only } \\
\text { telephone }\end{array}$ & $\begin{array}{c}\text { Only } \\
\text { telephone }\end{array}$ & $\begin{array}{c}\text { From } \\
\text { telephone }\end{array}$ \\
\hline 8 & Yes & Can access & Yes & No & $\begin{array}{l}\text { From } \\
\text { telephone }\end{array}$ \\
\hline 9 & Yes & $\begin{array}{c}\text { Not } \\
\text { necessarily } \\
\text { to a } \\
\text { particular } \\
\text { kind mail } \\
\text { account }\end{array}$ & $\begin{array}{l}\text { Just about } \\
\text { particular e- } \\
\text { mail aacount }\end{array}$ & $\begin{array}{l}\text { Just about } \\
\text { particular e- } \\
\text { mail aacount }\end{array}$ & Yes \\
\hline 10 & Yes & Can access & Yes & Yes & No \\
\hline 11 & Yes & Can access & Yes & Yes & Yes \\
\hline 12 & Yes & Can access & Yes & Yes & Yes \\
\hline 13 & Yes & Can access & Yes & Yes & No \\
\hline 14 & Yes & Can access & Yes & Yes & $\begin{array}{c}\text { From } \\
\text { telephone }\end{array}$ \\
\hline 15 & Yes & Can access & Yes & Yes & Yes \\
\hline
\end{tabular}

In table 6 have reached the following conclusions. Each social media site accepts users with e-mail information. Most sites allow users is the fact that they do not have e-mail addresses and user records. The aim is to prevent the user's record, while the tired and do this work on verification. Almost every site user wanted to use the confirmation e-mail. Very few sites allow users to become members only from mobile devices. The reason for this is to ensure the right people to be members as users of mobile devices. Because the mobile device is the user identifier. One social media site users to only accept certain kinds of e-mail accounts. The goal here is to ask users of the site owners only use their own products. This is not ideally suited for cloud environments. Some social media sites have requested the user's mail and address information to the requesting verification via a mobile device. This is the ideal situation when the current security mechanisms considered verification via mobile devices. But this time the users of a mobile devices themselves do not want to share that information with the site conditions may lower the rating. 


\section{Accessing from Devices}

Environments that provide access to social media sites showed differences as seen from Table 7. The site has seen its ten percentage of tested only they accept registration from the mobile environment. However, all sites accept users of the mobile environment [13]. It is expected to can bind at the site of each environment of normal. There are several reasons for this. The most important reasons that now users of the phone always as the transport and these devices often due to the lack of internet connection users of the site are always connected to the case look and or online on more systems than the normal environment. Some social media site is unique because it is unique to the account of the owner of the phone much more like this. But the only reason for the lack of the number of sites that accept user is more mobile than other users of these sites.

Table 7. Relationship between social media ranking and access from PC or mobile devices

\begin{tabular}{|c|c|}
\hline Ranking & Access from PC or mobile \\
\hline 1 & Both \\
\hline 2 & Both \\
\hline 3 & Both \\
\hline 4 & Both \\
\hline 5 & Both \\
\hline 6 & Both \\
\hline 7 & Both \\
\hline 8 & Both \\
\hline 9 & Only mobile \\
\hline 10 & Both \\
\hline 11 & Both \\
\hline 12 & Only mobile \\
\hline 13 & Both \\
\hline 14 & Both \\
\hline 15 & Both \\
\hline
\end{tabular}

\section{Conclusion}

In this paper, we explore various parameters that why end users rate one social website higher than the others. Moreover, we provided guidelines for future development of social media websites that they should at least incorporate the features that users want in terms of ease of use and excitement. By analyzing various data from popular social websites, we concluded that users want ease of use and good interactive websites with flexible ways to login. Moreover, the various criteria that users will prefer to join a social media website are shown below in Table 8 . 
Table 8. Relationship between social media criteria.

\begin{tabular}{|c|c|}
\hline Criterias & Currency \\
\hline Captcha using & First not later used \\
\hline Other social media sites supporting & Yes \\
\hline Minimum password length & 8 \\
\hline Have to use special characters in password & Yes \\
\hline Request a phone number & Yes \\
\hline Telephone number of different countries & Yes \\
\hline Corporate e-mail support & Yes \\
\hline In fact no e-mail & No \\
\hline Popular e-mail account support & Yes \\
\hline Sloopy mail & No \\
\hline Confirmation mail & Yes \\
\hline Access from PC or mobile & Both \\
\hline
\end{tabular}

\section{References}

[1] Anderson, Ross, Security engineering (John Wiley \& Sons, 2008).

[2] Kemp, Simon, "Digital, social \& mobile worldwide in 2015." We are social, Special Report (2015).

[3] "Top 15 Most Popular Social Networking Sites.”, last modified 12 March, 2016, http://www.ebizmba.com/articles/social-networking-websites.

[4] Baird, Henry S., Michael A. Moll, and Sui-Yu Wang, "ScatterType: a legible but hardto-segment CAPTCHA." (paper presented at the annual meeting for the Document Analysis and Recognition, 2005. Proceedings. Eighth International Conference on. IEEE, 2005).

[5] Duggan, M., “Social Media Update 2014.” Pew Research Center, (2015).

[6] Lamport, Leslie, "Password authentication with insecure communication." Communications of the ACM 24.11 (1981): 770-772.

[7] Singh, Ved Prakash, and Preet Pal, "Survey of different types of CAPTCHA." International Journal of Computer Science and Information Technologies 5.2 (2014): 2242-2245.

[8] Hoffman, Ned, "Token less biometric electronic transactions using an audio signature to identify the transaction processor." U.S. Patent No. 6,397,198 (2002). 
[9] Von Ahn, Luis, “CAPTCHA: Using hard AI problems for security." (paper presented at the annual meeting for the International Conference on the Theory and Applications of Cryptographic Techniques. Springer Berlin Heidelberg, 2003).

[10] Morris, Robert, and Ken Thompson, "Password security: A case history." Communications of the ACM 22.11 (1979): 594-597.

[11] Miller, M. F. “Mobile device authentication.” U.S. Patent No. 8,995-960 (2015).

[12] Husemann, Dirk. "Payment for network-based commercial transactions using a mobile phone." U.S. Patent Application No. 09/843,968 (2001).

[13] Jabeur, Nafaâ, Sherali Zeadally, and Biju Sayed, "Mobile social networking applications." Communications of the ACM 56.3 (2013): 71-79. 